\title{
AN ASSESSMENT OF THE POTENTIAL RETURNS OF ENERGY CERTIFICATES FOR THE UK HOUSEHOLD SECTOR.
}

\author{
C. McGilligan ${ }^{1}$, P. de Wilde ${ }^{1}$ and ${ }^{*}$ S. Goodhew ${ }^{2}$ \\ ${ }^{1}$ University of Plymouth, School of Engineering, Environmental Building Group, Plymouth, PL4 8AA, Devon \\ ${ }^{2}$ Nottingham Trent University, School of Architecture, Design and the Built Environment, Nottingham, NG1 4BU, \\ Nottinghamshire. *(corresponding author, contact phone number, 0115848 2582)
}

\section{Summary}

\section{Purpose}

This article investigates the interconnections between the expectations of the impact of energy certificates issued within the UK domestic building sector through the Energy Performance of Buildings Directive (EPBD) and the actual number and financial implications of the energy saving measures (ESMs) achieved.

\section{Design/methodology/approach}

The methodology uses two previously published surveys and compares these with a third independent survey by the authors focusing upon the discrepancies between planned action and implemented action, introducing the term human factor element ( $h f e)$.

\section{Findings}

The article concludes that annual carbon savings arising from implementation of the Energy Performance Certificate (EPC) may be as low as $73.4 \mathrm{ktC}$ over the 5 year term of the Kyoto Protocol even though $44 \%$ of energy saving measure costs of £200M are recouped within the same time period and savings will continue for up to 40 years. Achieving annual savings of only $14.7 \mathrm{ktC}$ by 2010, such a figure represents a mere $0.3 \%$ of the annual domestic 4.8MtC savings announced by the government in its 2006 Climate Change Programme.

\section{Practical implications}

Since the principal determinant in the uptake of ESMs is initial cost, it is considered that the EPBD is likely to remain an underperforming instrument in the promotion of energy sufficiency until such time as other complementary provisions are introduced.

\section{Originality/value}


Sheds light upon the likely financial impact upon energy efficiency in domestic buildings by energy certificates.

Keywords: energy certificates, annual carbon savings, efficient, homes, finiancial cost, human behaviour.

\section{INTRODUCTION}

The built environment accounts for some $40 \%$ of the total energy consumption across the European Union (EU) (EC, 2005). Furthermore, the Kyoto Protocol requires the UK to reduce its carbon dioxide emission levels to $87.5 \%$ of its 1990 level for the duration of the 5-year period 2008-2012 (DEFRA 2006c). Cogniscent of its duty to address the issue of profligacy with regard to the energy consumption of the built environment and the burden imposed by the Protocol, 2003 saw the implementation of the Energy Performance of Buildings Directive (EPBD) by the European Commission (EC, 2003).

Households are responsible for more than a quarter of the United Kingdom's total carbon dioxide emissions: 41.7 million tonnes of carbon $(M t C)$ of the 152.5 MtC emitted in 2004 (DEFRA, 2006b). However, the economic implications of certificate-led energy reductions should not be ignored, and interventions stemming from well-designed energy related policies can result in substantial financial as well as energy savings (Geller et al, 2006). Not only is there benefit to be gained in reduced energy bills following implementation of energy efficient measures, but there also exists a possible marketing advantage, similar to that seen with energy efficient commercial buildings (Guertler et al, 2005), over less energy efficient homes (Lorenz, 2007). In the context of the recent instability observed in energy prices/supplies and collapse in the housing market, the significance of this latter benefit in the current buyers' market should not be underestimated. However, some comentators are sceptical about the leverage this aspect will have with potential buyers (Marketwatch, 2006).

Article 7 of the EPBD specifically demands that when buildings are constructed, sold or let, an Energy Performance Certificate (EPC), indicating the amount of energy consumed with a standardised use of the building, is made available to the new owner, buyer or tenant. Key to the success of the EPBD is the fact that the EPCs must include cost-effective recommendations suggesting how energy performance might be improved through the application of Energy Saving Measures (ESMs). With the annual rate of residential property transactions in England being of 
the order of $10 \%$ (DCLG, 2006a), Article 7 bears the capacity to invoke extensive change over a relatively short timescale. It is the only element of the EPBD which has the potential to make a significant impact on the existing housing stock.

Other authors have found that energy conservation provision through design is highly influenced by cost and that people are unwilling to pay for technologies that will increase the purchase price without immediate payback (Adeyeye, 2007). Essentially a tool of communication, the EPC however, when allied to a form of subsidy such as a grant or tax rebate, could provide a vehicle for surmounting this obstacle in making clear the savings possible in short order. Similar linkages with regulation could have the same effect.

Santamouris (2007) reports in a study that only $28 \%$ of people of the poorest group surveyed live in insulated buildings, while the corresponding figure for the richest group surveyed is close to $70 \%$. Fuel poverty arises where householders must spend more than $10 \%$ of their incomes on energy to heat their homes to a comfortable level, and in connection with this, the EPC may also provide a vehicle to tackle this social injuctice by reducing the fuel bills of the poorest in society.

\section{OBJECTIVE}

This study sets out to investigate whether the EPC, which was first due to be introduced as part of the Home Information Pack (HIP) in June 2007, will, in its present form, be an effective instrument in promoting energy efficiency and contribute to the UK meeting its carbon reduction targets with regard to the Kyoto Protocol.

In the absence of auxiliary regulation or state-sponsored incentives, the success or failure of the EPC as a legislative tool in furthering the cause of energy efficiency simply resides in its capacity to persuade householders to adopt ESMs.

The EPC states the average costs for space heating, hot water and lighting, and further includes advice as to how to cut costs by incorporating ESMs (DCLG, 2006b). It includes an asset rating, categorising buildings from A (highly energy efficient) to G (not energy efficient). 
One of the major issues connected with the EPBD relates to the monetary gain, or, more accurately, potential savings to be made through the use of ESMs. The question is therefore asked as to whether or not the economic benefit to be gained through the implementation of the EPBD is sufficiently large so as to encourage a substantial number of householders to invest in ESMs.

\section{METHODOLOGY}

\section{Background on the impact of energy performance certificates}

The fact that EPCs have been little used in the past means that the amount of hard data obtainable from the literature is limited. Indeed, a research group from the University of Sheffield could find but one other study, a study carried out by the Environmental Change Institute at the University of Oxford, in addition to their own (Parnell and Popovic Larsen, 2005). Nonetheless, though the response rate was not particularly high in either (which, indeed, is revealing in itself, speaking perhaps of the larger public's attitude to the issue of energy efficiency), these two surveys have generated a sufficiently large quantity of data upon which further analysis can be performed.

\section{Human factor element}

A great disadvantage of surveys which endeavour to describe the future which involve individuals stating that which they plan to do, is that there often exists a discrepancy between the number of tasks that individuals intend to carry out and the actual number that they complete. Succinctly, within any given timeframe, individuals tend to carry out rather fewer tasks than they had intended. This misalignment between that which householders claim themselves as willing to do and that which they actually do with respect to energy efficiency is made clear in research commissioned by Powergen and carried out by the University of East Anglia. Although more than a third of householders claim to be willing to pay 5 to $10 \%$ more for green electricity (Tinch et al, 2003), the voluntary consumer market for such accounts for a mere $0.2 \%$ of the total demand for UK electricity (Friends of the Earth, 2004) even though more than $4 \%$ of electricity is estimated to derive from renewable sources (DTI, 2006a). Since this investigation makes use of a questionnaire which requires householders to state their intended actions, account has to be taken of this misalignment such that the number of intended actions is scaled down to the number that is actually carried out. This study terms the scaling-down factor the human factor element (hfe). 
Describing the ratio of the number of energy saving measures that householders actually carry out to the number that they intend to implement, the behaviourist approach thus adopted goes some way to circumvent the problem where there exists a disparity between intention and actual observed action.

\section{Procedure}

The study makes use of three surveys, two of which are drawn from the literature (Surveys 1 and 2). The homeowners from Surveys 1 and 2 were issued with EPCs (supplied by the Woolwich plc in association with Ekins Surveyors). Complementary in nature, their worth amounts to more than the sum of their component parts since only together can Surveys 1 and 2 be used to predict the uptake of ESMs in the future. The third survey (Survey 3) was conducted to investigate the discrepancy between planned action and implemented action.

The procedure involved consists of two stages (A and B). Stage A (Surveys 1 and 2) quantifies the effect of the EPC by establishing the value of the energy certificate factor $(f)$, the factor by which the EPC increases the rate of uptake of ESMs. Stage B (survey 3) examines the model's robustness as a calculation tool of ESM uptake by comparing the level of ESM uptake by an independent third group of householders with the level the model predicts. This overall approach is depicted in figure 1 below.

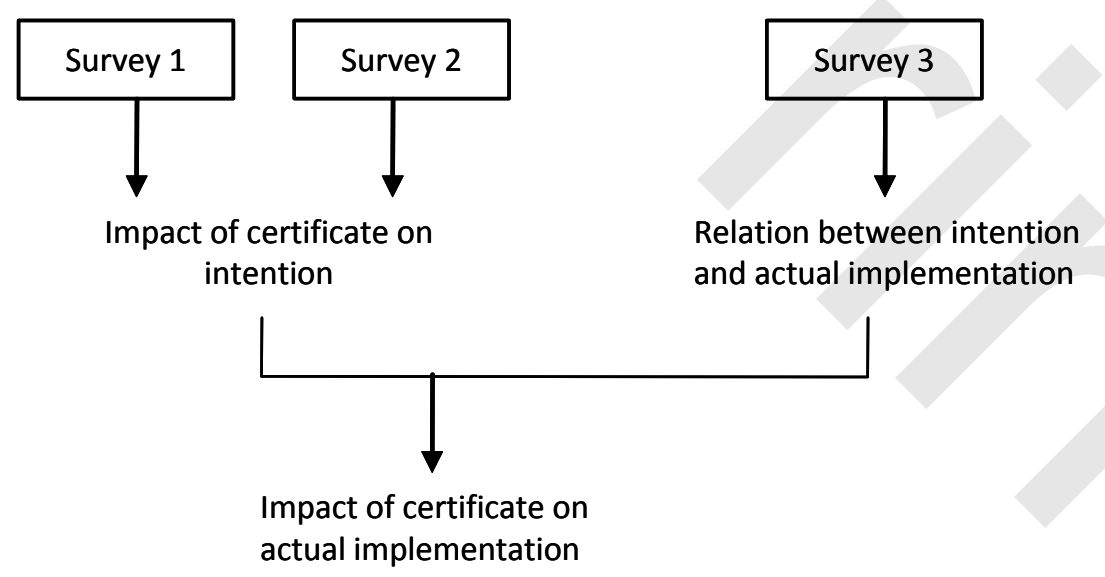
National $\mathrm{CO}_{2}$ trend
without certificate

Impact of certificate on national $\mathrm{CO}_{2}$ trend 


\section{Stage A - A review of data from previous studies}

Energy certificates were issued to a group of 2000 householders upon purchase of their new homes (Survey 1) (Parnell and Popovic Larsen, 2005). Approximately a year later a sub-sample of 20 were surveyed in order to determine whether or not their intentions had been turned into actions. There was a discrepancy between the two, such discrepancy being described by the afore-mentioned human factor element (hfe) which lies at the heart of this article.

Energy certificates were issued to another group of 2000 householders upon purchase of their new homes (Survey 2) (Darby, 2003). Approximately 14-20 months after purchase, a survey of 66 of the householders was carried out in order to establish (i) the number of ESMs householders had introduced in the initial 17 month period (mid-point of 14-20 months) of residence, and (ii) the number that they intended to introduce in the subsequent six months. The assumption is made that if a householder is going to implement an ESM recommendation contained within the EPC, he/she will do so in the 20-26 month period of residence (14-20 months + 6 months) following receipt of the certificate (ie mid-point of 23 months) (see Error Analysis).

The resultant impact of the energy certificate, the proportion by which it increases the uptake of ESMs in the post-transaction period is termed the energy certificate factor) $(f)$,

where

$f=N / N_{\text {bau }} \ldots \ldots \ldots \ldots \ldots \ldots \ldots . . .(1)$

where

$N=$ number of ESMs implemented per household following issue of the EPC

$N_{\text {bau }}=$ number of ESMs implemented per household under the business-as-usual scenario

and

$N=N_{a}+h f e x N_{i}$

$N_{a}=$ the number of ESMs actually carried out per household in the 14-20 month period (average

17 months) following transaction, 
$N_{i}=$ the number of ESMs intended to be implement per household in the following six months

The resultant carbon savings are derived from the following equation

where

$\Delta C=k x t\left[\left(f x E_{2008-2012}\right)-E S M_{2008-2012}\right]$

where

$\Delta C=E P C$-induced carbon savings (2008-2012)

$k=$ carbon conversion factor, carbon savings arising from installation of an ESM in a stocktypical home

$t=$ national transaction rate

$E S M_{2008-2012}=$ nationwide ESM uptake which would have occurred in absence of EPC in the posttransaction period

\section{Stage B - New data / control survey}

A questionnaire (see appendix) was sent out to 49 householders selected from a representative population known to the authors, (thus encouraging a good return rate but having the disadvantage of not being fully representative) for (Survey 3) (See Error Analysis).

The number of ESMs carried out in the first 23 months of residence $\left(N_{\text {bau }}{ }^{1}\right)$ was ascertained.

The model critically relies upon the assumption that the base level of uptake of ESMs by the sample group in Survey 2 is representative of the wider population (equation 2). If the assumption holds true, the model should be able to predict the base level of uptake of ESMs by a third independent group (Survey 3 group) by regression. The energy certificate factor being the factor by which the base level of uptake of ESMs is boosted by the EPC, it can be expressed thus:

$f=\left(N_{r}+N_{b a u}\right) / N_{b a}$

where

$N_{r}=$ number of ESMs implemented in response to the EPC.

Rearrangement of equation 4 results in an expression which describes the number of ESMs carried out in the first 23 months of residence in the business-as-usual scenario $\left(N_{\text {bau }}\right)$, 
$N_{\text {bau }}=N_{r} /(f-1)$

The value of $N_{b a u}$ predicted by the model would be expected to be in close accord with $N_{b a u}{ }^{l}$ if the assumption that the sample group in survey 2 is representative of a wider population is correct. The robustness factor $(r)$ measures the degree to which the model over- or under-estimates ESM uptake and is described in equation 6 where

$\left.r=\left(N_{\text {bau }}-N_{\text {bau }}{ }^{l}\right) \times 100 / N_{\text {bau }}{ }^{l}\right)$

\section{RESULTS}

Tables 1- 5 show the results of the previous equations in conjunction with the three surveys;

\begin{tabular}{|l|c|}
\hline ESM & $\boldsymbol{r}(\boldsymbol{\%})$ \\
\hline Draught-proofing & -50 \\
\hline Loft insulation/additional loft insulation & -56 \\
\hline Cavity wall insulation & -25 \\
\hline Hot water tank insulation & -46 \\
\hline Double glazing & 46 \\
\hline
\end{tabular}

Where the closer $r$ approaches a value of 0 , the more robust the model.

Table 1

Intended and actual uptake of ESMs

\begin{tabular}{|l|c|}
\hline ESMs intended & 21 \\
\hline ESMs implemented of those recommended & 15 \\
\hline Human factor error $(\mathrm{hfe})$ & 0.714 \\
\hline
\end{tabular}

Table 2

Robustness Factor ( $r$ ) \%

\begin{tabular}{|l|c|c|}
\hline ESM & $\boldsymbol{f}$ & $\Delta \boldsymbol{C}(\boldsymbol{k t} \boldsymbol{C})$ \\
\hline Draught-proofing & 1.857 & 11.5 \\
\hline Loft insulation (DIY) & 1.571 & 12.8 \\
\hline $\begin{array}{l}\text { Loft insulation } \\
\text { (professionally installed) }\end{array}$ & 1.571 & 5.5 \\
\hline Cavity wall insulation & 2.333 & 29.0 \\
\hline Hot water tank insulation & 1.200 & - \\
\hline Double glazing & 1.039 & 14.6 \\
\hline & & \\
\hline Total & & 73.4 \\
\hline
\end{tabular}

Table 3

Energy certificate factor $(f)$ and carbon savings $(\Delta C)$ (for duration of Kyoto Protocol term (2008-2012 inclusive)

\begin{tabular}{|l|c|c|c|c|c|c|}
\hline & $\mathbf{2 0 0 8}$ & $\mathbf{2 0 0 9}$ & $\mathbf{2 0 1 0}$ & $\mathbf{2 0 1 1}$ & $\mathbf{2 0 1 2}$ & $\mathbf{2 0 0 8 - 2 0 1 2}$ \\
\hline Draught-proofing & 0.46 & 1.38 & 2.30 & 3.22 & 4.14 & 11.5 \\
\hline Loft insulation (DIY) & 0.51 & 1.54 & 2.56 & 3.58 & 4.61 & 12.8 \\
\hline Loft insulation (prof) & 0.22 & 0.66 & 1.10 & 1.54 & 1.98 & 5.5 \\
\hline Cavity wall insulation & 1.16 & 3.48 & 5.80 & 8.12 & 10.44 & 29.0 \\
\hline
\end{tabular}




\begin{tabular}{|l|c|c|c|c|c|c|}
\hline Double glazing & 0.58 & 1.75 & 2.92 & 4.09 & 5.26 & 14.6 \\
\hline TOTAL & $\mathbf{2 . 9}$ & $\mathbf{8 . 8}$ & $\mathbf{1 4 . 7}$ & $\mathbf{2 0 . 6}$ & $\mathbf{2 6 . 4}$ & $\mathbf{7 3 . 4}$ \\
\hline
\end{tabular}

Table 4

Nationwide carbon savings $(\boldsymbol{k t C})$ brought about by the EPC throughout the term of the Kyoto Protocol

\begin{tabular}{|l|c|c|c|c|}
\hline & $\begin{array}{c}\text { ESM } \\
\text { INSTALLATION } \\
\text { COST (EM)* }\end{array}$ & $\begin{array}{c}\text { FUEL COST } \\
\text { SAVINGS } \\
\text { (EM)** }\end{array}$ & $\begin{array}{c}\text { PROPORTION OF } \\
\text { INSTALLATION } \\
\text { ACHIEVED THROUGH } \\
\text { FUEL COST SAVINGS } \\
\text { (\%) }\end{array}$ & $\begin{array}{c}\text { ESM LIFETIME } \\
\text { (YEARS)*** }\end{array}$ \\
\hline $\begin{array}{l}\text { Draught- } \\
\text { proofing }\end{array}$ & 27.707 & 15.728 & 57 & 20 \\
\hline $\begin{array}{l}\text { Loft insulation } \\
\text { (DIY) }\end{array}$ & 18.351 & 17.679 & 96 & 40 \\
\hline $\begin{array}{l}\text { Loft insulation } \\
\text { (professional) }\end{array}$ & 16.188 & 7.622 & 47 & 40 \\
\hline $\begin{array}{l}\text { Cavity wall } \\
\text { insulation }\end{array}$ & 56.762 & 40.795 & 72 & 20 \\
\hline Double glazing & 81.515 & 6.538 & 8 & \\
\hline TOTAL & $\mathbf{2 0 0 . 5 2 3}$ & $\mathbf{8 8 . 3 6 2}$ & 44 & \\
\hline
\end{tabular}

* Based on DEFRA estimates for 2010 (DEFRA, 2008), using GDP deflator value of $23 \frac{3}{4} \%$ as forecast by HM Treasury (HM Treasury, 2008).

** Based on DEFRA estimates for 2007 (DEFRA, 2008), taking account of the 11.8\% increase in domestic energy prices from 2nd quarter 2007 to April 2008 (BERR, 2008) and using GDP deflator value of 23/4\% as forecast by HM Treasury (HM Treasury, 2008).

***DEFRA, 2008

Table 5

Comparsion of nationwide (UK) installation costs and financial savings over the course of the Kyoto Protocol term(2008-2012)

Thus using the figures from the above tables to summarise the impacts to the UK of the EPBD over the Kyoto Protocol term- $\mathrm{CO}_{2}$ savings 73.4 ktc, ESM costs £201m, fuel cost savings £88m

\section{ERROR ANALYSIS}

Given that the calculation of $\Delta C$ derives from a series of dependent steps, the possibility of accruing cumulative error is significant. The factors impinging upon the calculation of $\Delta C$ are discussed in turn. 


\section{Carbon conversion factor $(k)$}

The carbon conversion factor is a measure of the carbon savings which result following installation of an ESM in a stock-typical semi-detached house. The carbon conversion factor values for each particular ESM are government figures sourced directly from DEFRA (DEFRA, 2007) using the Building Research Establishment Domestic Energy Model (BREDEM) (BRE, 1985). It should be pointed out that the nature of air infiltration is such that it is impossible to be precise with respect to the assignation of specific values to draught-stripping measures (DEFRA, 2007).

\begin{tabular}{|c|c|}
\hline & $\begin{array}{c}\text { CARBON CONVERSION } \\
\text { FACTOR }(\boldsymbol{k}) \text { (tC/vr) }\end{array}$ \\
\hline Draught-proofing & $0.43^{*}$ \\
\hline Loft insulation (DIY) & $0.086^{*}$ \\
\hline Loft insulation (professional) & $0.10^{*}$ \\
\hline Cavity wall insulation & $0.20^{*}$ \\
\hline Hot water tank insulation & $0.053^{*}$ \\
\hline Double glazing & $0.74^{* *}$ \\
\hline
\end{tabular}

* for stock-typical semi-detached house (DEFRA, 2007)

$$
\text { ** EST, } 2008
$$

Table 6 Carbon conversion factor $(k)$

\section{Human factor error $(h f e)$}

Relying upon a sample group of 20 householders to whom 21 recommendations were made (Survey 1), the small size of the survey is far from ideal. Furthermore, the $h f e$ is assumed to act equally across the board, being as applicable to the less expensive installed ESMs as to the more expensive ESMs. This is unlikely to be the case in reality. Examination of the data from Survey 1 reveals, for example, that the actual uptake of energy-saving light bulbs (ESLs) was even higher than the intended uptake, the suggestion being that their use is becoming so commonplace as to shortly become mainstream even in the absence of the EPC. In addition, it is presumed that $h f e$ acts constantly over time: whilst measured over the first 12 months of residence, it is applied to a term of up to 26 months in duration.

\section{National transaction rate $(t)$}


Derivation of $\Delta C$ is strictly dependent upon the value chosen for the national transaction rate, the transaction figures for non-newly-built owner-occupier homes in England being used as the basis of the calculation in this instance. The fact that newly-built private homes and homes which are let are excluded from the transaction figures is believed to enhance the accuracy of the model. Since private tenancies only constitute $11 \%$ of all tenures and $69 \%$ of tenants stay no longer than 3 years in the one home (DCLG, 2006d), it is unlikely that this sub-group of householders will implement many ESMs as there is little incentive for them to do so as costs may never be recouped. As for the $19 \%$ of households renting from registered social landlords or local authorities (DCLG, 2006d), again there is little reason for such tenants to install ESMs as these matters largely fall under the responsibility of the landlord. Although the EPC must also be provided to the owners of newly built houses, it is reasonable to assume that the EPC will have little impact upon these householders since new houses are, for the most part, built to the much improved thermal requirements of Approved Document L1A and, furthermore, only account for 0.8\% of housing (DCLG, 2006d). Whilst there is scope for error in assuming that the transaction rate observed in England is representative of the country as whole, this assumption is deemed to be of minor significance since the vast majority of the UK housing stock (83\%) is in England (DCLG, 2006d).

\section{Base level ESM uptake 2008-2012 (ESM 2008-2012)}

Calculation of $\Delta C$ assumes that the consistency observed in the historical trend of ESM uptake would continue into the near future at the same rate as before in the absence of an EPC. Since this underlying rate of uptake has been remarkably steady for at least 14 years for 5 of the 6 ESMs listed, any variance over the three year period 2008-2012 is likely to be relatively minor in magnitude. Hot water tank insulation providing the exception, its rate of uptake has borne so little consistency in the recent past as to make predictions concerning future uptake redundant.

In similar vein, the forecast makes the assumption that the effectiveness of the EPC does not change with time, so that its measured effect upon increased ESM uptake will not change over the course of the period 2008-2012. (This assumption is difficult to test; although it is expected that 
its effectiveness will increase over time, it is reasonable to assume that its effectiveness will not alter radically over the course of the five years as the inertia driving the process will still be in its infancy).

\section{Energy certificate factor $(f)$}

$f$ is the factor by which the EPC augments the implementation of ESMs in the post-transaction period. In view of the fact that it is affected by the value given the length of the post-transaction period, there is likely to be error since it is clear that the EPC will not abruptly stop being effective after 23 months. Rather its effectiveness is likely to incrementally diminish with time. However, the DTI report that the vast majority of home improvements are carried out within 6 months of the purchase of a property (DTI, 2006b).

As $f$ is necessarily dependent upon the initial pre-certification level of ESMs incorporated within dwellings, discrepancies between the sample group in Survey 2 and the nation as a whole will adversely affect the calculated value of $f$. Indeed, this does appear to be the case, no doubt arising from the small size of the sample group, where the Survey 2 respondents possess $38 \%$ less loft insulation than the national average but $40 \%$ and $65 \%$ more cavity wall insulation and double glazing (most windows) respectively (Darby 2003). The combination of the misestimates tends towards an overall underestimation of $f$, the carbon conversion factor value of cavity wall insulation being approximately twice that of loft insulation. Survey 3, which specifically attempts to evaluate variation within population groups through $r$ scores, shows there to be a considerable discrepancy between the predicted uptake of ESMs and the actual uptake of ESMs.

\section{Robustness factor ( $r$ )}

Sources of error - As with any voluntary survey of the public, a non-representative cross-section is likely to have been engaged. Those who reply are more likely to be interested in the subject matter and are therefore more likely to implement ESMs. $r$ fails to take account of this. Nevertheless, the advantage offered by the sampling method employed ( ie a near $100 \%$ response rate) is deemed to so far outweigh this deficiency as to merit its use, the response rate with the random sampling technique employed in Survey 2 being low (3.5\%). 
Whilst the householders in Surveys 1 and 2 all bought their homes between 1999 and 2001, those from Survey 3 bought them over a much longer time frame ranging between 4 weeks and 35 years; given the lesser availability of ESMs in the past, one would have expected actual uptake to be lower than predicted uptake.

In the absence of documentation it is likely to be a rare occurrence where the human memory can specifically pinpoint in time the implementation of an ESM when the event occurred at some distant point in the past. It is reasonable to assume though, that as many ESMs were incorrectly remembered as occurring within the first 23 months of residence as beyond the first 23 months. Evaluation - Notwithstanding the disparity between the predicted uptake and actual uptake of ESMs, there is a certain degree of consistency between the two for the most important ESMs (ie those where the carbon savings are likely to be greatest and for which the outlay is least). Although the model under-predicted uptake, a mere $10 \%$ (-46\% to $-56 \%)$ difference separates the values for draught-proofing, loft insulation and hot water tank insulation. Whilst the $r$ value for cavity wall insulation is $-25 \%$, again the value is an under-prediction. There is, however, likely to be some error in the $r$ value for draught-proofing, such measures as new external doors being included as a draught-proofing ESM by certain of the respondents in Survey 3. When these new component measures are exluded, the $r$ value drops to $-19 \%$, nevertheless, still a considerable under-prediction. The fact that the uptake of double glazing is overestimated is of less significance than it might be since the impact of the EPC on its uptake is considerably smaller than for the other ESMs, its uptake being augmented by less than $4 \%(f=1.039)$,

\section{DISCUSSION OF RESULTS}

If the EPC is to be effective as a tool of communication, one would expect a disproportionately large uptake of those ESMs saving the most money and for which the capital outlay was the least. The payback time of such measures being tantamount to the combined effect of these two measures, table 7 compares the uptake due to the EPC (f) and the payback time. 


\begin{tabular}{|l|c|c|}
\hline ESM & $\boldsymbol{f}$ & $\begin{array}{l}\text { PAYBACK TIME } \\
\text { (YRS) }\end{array}$ \\
\hline Draught-proofing & 1.9 & 4.3 \\
\hline Loft insulation & 1.6 & 2.7 \\
\hline Cavity wall insulation & 2.3 & 2.6 \\
\hline $\begin{array}{l}\text { Windows (single to } \\
\text { double glazing) }\end{array}$ & 1.0 & $43.7^{* *}$ \\
\hline Hot water tank insulation & 1.2 & 0.5 \\
\hline
\end{tabular}

Table 7

Comparison of energy certificate factor (f) with payback time

* (DCLG 2006c)

** based on carbon savings cited by the Energy Saving Trust (EST, 2008)

* (; DEFRA, 2006d; DEFRA, 2007).

Table 7 does show a certain degree of correlation between the EPC (f) and the payback time. For example, the low value of the EPC (f) for upgrading single glazed windows is undoubtedly a reflection of the long payback period. Similarly, the relatively high EPC (f) values of 1.6 and 2.3 for loft insulation and cavity wall insulation are in accord with their low payback times of 2.7 and 2. 6 years respectively. These large increases in uptake are understandable when it is realised that $72 \%$ of the nationwide $£ 66 \mathrm{M}$ costs resulting from installation of these two measures are redeemed within the five year period of the Kyoto Protocol term and that the ESMS will continue to produce savings for another 35 years as shown in table 5. The carbon savings associated with these measures being the greatest, such correspondence is important, suggesting that there might be a role for the EPC to play as a tool of communication.

The disproportionately high uptake of draught-proofing measures, despite the longer payback time, may be rather more related to issues concerning comfort/health rather than energy efficiency and carbon emissions. The relatively low uptake of hot water tank insulation can, at least in part, be explained by the fact that hot water tanks are becoming increasingly démodé as householders replace their conventional boilers with combination boilers which do not require hot water tanks. As such, householders may be reluctant to invest in an ESM which will soon become redundant. Leaving aside hot water tank insulation therefore, it is interesting to note the comparison between initial outlay and uptake as is shown in table 8. 


\begin{tabular}{|l|c|c|}
\hline ESM & $\boldsymbol{f}$ & $\begin{array}{l}\text { INSTALLATION } \\
\text { COST/HOUSEHOLD } \\
\text { (£) (2008 PRICES)* }\end{array}$ \\
\hline Draught-proofing & 1.9 & 98 \\
\hline Loft insulation (DIY) & 1.6 & 117 \\
\hline $\begin{array}{l}\text { Loft insulation } \\
\text { (professional) }\end{array}$ & 1.6 & 279 \\
\hline Cavity wall insulation & 2.3 & 370 \\
\hline $\begin{array}{l}\text { Windows (single to } \\
\text { double glazing) }\end{array}$ & 1.0 & $3114^{* *}$ \\
\hline $\begin{array}{l}\text { Hot water tank } \\
\text { insulation }\end{array}$ & 1.2 & 13 \\
\hline
\end{tabular}

* based on data from DEFRA, 2008

** based on data from DCLG, 2006c

Table 8

Comparison of energy certificate factor $(f)$ with installation costs

The installation costs might not only explain the very low uptake of expensive double glazing, but also explain the anomaly provided by inexpensive draught-proofing, its uptake being relatively large in comparison to the carbon savings available as determined by the $\mathrm{k}$ value.

\section{EVALUATION OF PREDICTED PERFORMANCE OF THE EPBD}

With policies put in place by the Government in its Climate Change Programme expected to produce annual household savings of $4.8 \pm 0.2$ MtC (DEFRA, 2006a; DEFRA, 2006b), the resultant domestic emission rate is calculated to be $36.5 \mathrm{MtC}$ per annum by 2010. Since the current intended application of Article 7 of the EPBD only amounts to annual household savings of the order of $14.7 \mathrm{ktC}$ by 2010 ( $0.4 \%$ of the Climate Change Programme total), it is clear that the EPC is likely to be a relatively ill-performing tool in instigating change. The Government's expectation of the EPC is similarly low with the combined total domestic savings deriving from (i) the Sustainable Buildings Code, (ii) the Energy Performance of Buildings Directive (ie not only Article 7), (iii) the commitment on procuring public buildings, and (iv) further measures coming out of the review of the existing building stock expected to account for only $0.1 \mathrm{MtC}$ (2\%) of the total 4.8 MtC achieved by the domestic sector (DEFRA, 2006b). Succinctly, the model's forecast annual savings of $14.7 \mathrm{ktC}$ by 2010 deriving from Article 7 by owner occupiers is in broad agreement with the Government's own relatively low expectations of the EPBD. 


\section{Basis of the Malfunction}

The authors expect that the following factors might contribute to the low impact of EPCs on actual carbon emission reductions:

High Initial Costs - Up-front costs appear to be a much more important determinant in consumers' decisions as to whether or not to implement an ESM than possible savings arising thereafter, a survey finding that for loft insulation and cavity wall insulation, the coefficient on costs $\left(k_{c}\right)$ is at least an order of magnitude greater than the coefficient on savings $\left(k_{c}\right)$, where

$P=\left(k_{c} x\right.$ cost $)+\left(k_{c} x\right.$ savings $)+$ constants

where $P=$ probability of installing ESM (Oxera, 2006).

The fact that the expensive double glazing was by far the least popular ESM to be installed despite offering large savings, whilst the inexpensive draught-proofing was taken up in relatively large numbers even though only offering modest savings in comparison as determined by the carbon conversion factor, further supports this point of view. Simply, if insufficient funds are available it appears that an ESM will not be implemented irrespective of the realisable savings.

Opportunity Cost - Though a cost-benefit analysis may show the implementation of an ESM to be worthwhile, the opportunity forsaken in spending the capital elsewhere cannot be ignored. Householders have a finite amount of capital available to them, and energy efficiency is not necessarily the item of most importance to a new homeowner who may have a number of other competing draws on his/her resources.

Inconvenience Factor - Action has to be taken to install an ESM. The associated aggravation caused by the implementation of an ESM, whether it be (i) the time taken to find, evaluate \& apply information about the ESM and suppliers, or (ii) the time and disruption caused by the process of implementation, cannot be underestimated.

Lack of knowledge - Householders can be reluctant to assume what can be perceived as a risk, at least in relation to the installation of insulation by unaccredited contractors. Irrespective of the fact that a high proportion of installers are accredited, only $8 \%$ of householders are aware of installer accreditation schemes ([Energy Saving Trust] cited by Oxera, 2006), the inference being that there exists an underlying fear of a rogue element within the trade. 
Lack of interest - Inextricably linked to each of the four explanations listed above, the heart of the problem may lie in simple lack of interest on the part of the consumer. Whilst householders have become ever greater consumers over the last 35 years, until very recently, energy has become significantly less expensive over the same time period (BRE, 2003). Additionally, the public seem to be unconcerned with the absolute quantity of capital savings realisable, energy efficiency labels which merely list energy performance alphabetically being found to be no less effective than those labels which actually quantify the savings per annum (Oxera, 2006).

\section{IMPROVEMENTS TO THE EPBD}

Taking these findings into consideration, the EPC may be considered as being fundamentally flawed and in need of amendment if it is to be an effective tool in delivering carbon savings. Review of the data over a period in excess of 20 years has shown that subsidy has been an effective instrument in reducing carbon emissions as a consequence of increased uptake of ESMs. ESM grant-awarding schemes from the period 1978-2000 are currently producing savings of 1.8 MtC/year, the overall net cost per tonne of carbon saved amounting to £272/tC (BRE, 2001). Whether the subsidy takes the form of (i) the issue of a grant, (ii) a reduction in Stamp Duty, (iii) a reduction in Council Tax (UK locally administered taxes levied for local services), (iv) mortgage interest tax relief, (v) a reduction in VAT (UK national purchase taxation) or (vi) a low interest loan (Parnell and Popovic Larsen, 2005; DEFRA, 2004 [Energy Efficiency Innovation Review] cited by Oxera, 2006), the EPBD is well placed to take advantage of any government subsidy passed its way.

\section{FUTURE WORK}

Since the research was compiled, matters have changed, with the Government deciding to delay the introduction of the HIP. Homes with four or more bedrooms have required them from 1 August 2007, those with three bedrooms from 10 September 2007 (DCLG, 2007a), and those with one or two bedrooms from 14 December 2007 (DCLG, 2007b). The current credit squeeze (due in part to the influence exerted by US sub-prime loan defaulters creating difficulties for 
lenders such as the UK’s Northern Rock Bank) and predictions of possible rises in unemployment (Conway Telegraph, 2008) may divert attention away from the need for energy reduction, and the laudable aims of energy certificates may become even further overlooked. As the implementation of the policies associated with Energy Performance of Buildings Directive (EPBD) roll out into the market place, it will be very interesting to see if the patterns indicated by this work are repeated and to what extent. The householders' assessment of their financial resources and their priorities in changing market conditions is likely to be a very fruitful future line of enquiry.

\section{CONCLUSIONS}

The model described in this study predicts that annual savings in 2010 deriving from owner occupiers as a result of implementation of Article 7 of the EPBD will only amount to $14.7 \mathrm{ktC}$, only $0.3 \%$ of the expected $4.8 \pm 0.2 \mathrm{MtC}$ total domestic savings deriving from the government's Climate Change Programme. Although 44\% of energy saving measure costs of £200M are recouped within the 5 year term of the Kyoto Protocol, the EPC will only bring about carbon savings of 73.4MtC over the same timeframe.

Allowing for the facts that (i) the model errs on the side of caution in tending towards the worst case scenario, and (ii) the small sizes of the sample groups used therein hamper the authority of the findings presented, the underpinning methodology is sound for short-term prediction. Although the model, on the whole, under-predicts the uptake of ESM, (a good measure of reservation being required in accepting the absolute values of any figures the model predicts), it is far less perilous to state that the model might be used as a worst case scenario predictor of ESM uptake. What is more, the savings predicted by the model are in broad alignment with the apparently low expectations that the Government has of the EPBD as a whole. Even allowing for an error of several hundred per cent, until such time as the Government commits to introducing further fiscal policy to sit alongside it, the potential that resides within the EPBD is likely to remain unlocked. 


\section{REFERENCES}

Adeyeye, K., Osmani, M. and Brown, C., 2007. Energy conservation and building design: the environmental legislation push and pull factors Structural Survey; 25, 5, 375-390.

BERR (Department for Business Enterprise and Regulatory Reform), 2008. Quarterly energy prices: tables - Retail prices index UK: fuel components monthly figures. London.

BRE (Building Research Establishment), 2001. Carbon emission reductions from energy efficiency improvements to the UK housing stock. Watford: BRE (Report 435).

BRE (Building Research Establishment), 2003. Domestic Energy Fact File 2003. Watford: IHS BRE.

Conway, E., 2008, Daily Telegraph, Property Supplement, Saturday 5th January 1-1.

Darby, S., 2003. Awareness, action and feedback in domestic energy use. Thesis (PhD).University of Oxford.

DCLG (Department for Communities and Local Government), 2006a. Housing in England 2003/04 - A report principally from the 2003/04 Survey of English Housing. London.

DCLG (Department for Communities and Local Government), 2006b.Government launches compulsory energy rating for homes to help cut carbon emissions. New measures could help tackle climate change. London.

DCLG (Department for Communities and Local Government), 2006c. Review of sustainability of existing buildings: The Energy Efficiency of Dwellings - Initial Analysis. London. 
DCLG (Department for Communities and Local Government), 2006d. Housing Statistics 2006. Norwich: The Stationery Office.

DCLG (Department for Communities and Local Government), 2007a. Next stage for Home Information Packs and Energy Performance Certificates announced. London.

DCLG (Department for Communities and Local Government), 2007b. Full Roll out of HIPS . London, DCLG.

DEFRA (Department for the Environment, Food and Rural Affairs), 2006a. Projected Savings from Climate Change Programme Policies in Households: Changes since the April 2004 Energy Efficiency Action Plan. London.

DEFRA (Department for the Environment, Food and Rural Affairs), 2006b. Climate Change The UK Programme 2006. Norwich: The Stationery Office.

DEFRA (Department for the Environment, Food and Rural Affairs), 2006c. Demonstrable Progress - The United Kingdom's Report on Demonstrable Progress under the Kyoto Protocol. London.

DEFRA (Department for Environment, Food and Rural Affairs), 2006d. The first draft Illustrative Mix of measures for the Energy Efficiency Commitment 2008-2011. London. 
DEFRA (Department for Environment, Food and Rural Affairs), 2007. Energy, cost and carbon saving calculations for the draft EEC 2008-2011 Illustrative Mix (Energy Efficiency Commitment 2008-11). London.

DEFRA (Department for Environment, Food and Rural Affairs), 2008. Explanatory Memorandum to the Electricity and Gas (Carbon Emissions Reduction) Order 2008. London.

DTI (Department of Trade and Industry), 2006a. UK Energy Sector Indicators 2006. London.

DTI (Department of Trade and Industry), 2006b. The Energy Challenge. Norwich: The Stationery Office.

EC (European Commission), 2003. Council Directive 2002/91/EC of 16 December 2002 on the energy performance of buildings. Official Journal of the European Communities. Brussels: The European Parliament and the Council of the European Union, (L 1 of 04/01/2003, 65-71).

EC (European Commission), 2005. Report on the Green Paper on Energy - Four years of European initiatives. Brussels: European Commission.

EST (Energy Saving Trust), 2008. Energy saving glazing. London http://www.energysavingtrust.org.uk/energy_saving_products/types_of_energy_saving_recomme nded_products/energy_saving_glazing

Friends of the Earth, 2004. Friends of the Earth Guide to Green electricity Tariffs - Background Document. London, Friends of the Earth. 
Geller, H., Harrington, P., Rosenfeld, A., Tanishima, S., and Unanderd, F., 2006. Polices for increasing energy efficiency:Thirty years of experience in OECD countries Energy Policy, 34, 5, 556-573.

Guertler, P., Pett, J., Kaplan, Z. (2005), Valuing low energy offices: the essential step for the success of the Energy Performance of Buildings Directive, Proceedings of the 2005 ECEEE Summer Study on Energy Efficiency, European Council for an Energy-Efficient Economy, Paris, 295-305.

HM Treasury, 2008. Budget 2008 - Stability and opportunity: building a strong, sustainable future. London: The Stationery Office.

Lorenz, d., Trück, S., and Lützkendorf, T., 2007, Exploring the relationship between the sustainability of construction and market value Property Management, 25, 2, 119-149.

MarketWatch, 2006, Energy Performance Certificates: selling energy efficient homes, Financial Services, 5, 10, 6-6.

Parnell, R. and Popovic Larsen, O., 2005. Developing the home energy report: An everyday householder-centred approach. Energy and Buildings, 37, 1092-1103.

Oxera, 2006. Policies for energy efficiency in the UK household sector-Report prepared for DEFRA. Oxford, Oxera Consulting Ltd. 
Santamouris , M., Kapsisa, K., Korresa, D., Livadaa, I., Pavloua, C., and Assimakopoulosa, M., 2007, On the relation between the energy and social characteristics of the residential sector, Energy and Buildings 39, 8, 893-905.

Tinch, M., Peters, M., Diaz-Rainey, I., Monahan, J., Waddams, C. and Tovey, K., 2003. Powergen Energy Monitor 2003 Highlights. London: Powergen. 
Figures and Tables

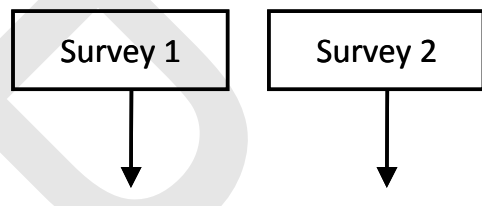

Impact of certificate on
intention

Relation between intention and actual implementation

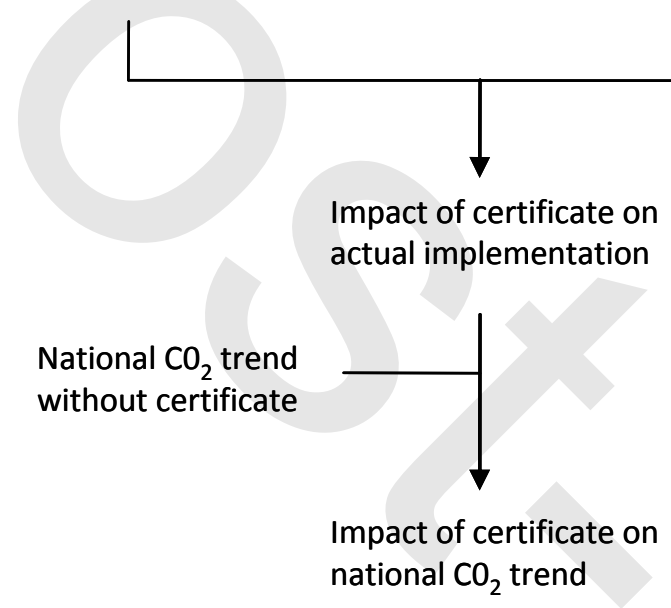




\begin{tabular}{|l|c|}
\hline ESM & $\boldsymbol{r}$ (\%) \\
\hline Draught-proofing & -50 \\
\hline Loft insulation/additional loft insulation & -56 \\
\hline Cavity wall insulation & -25 \\
\hline Hot water tank insulation & -46 \\
\hline Double glazing & 46 \\
\hline
\end{tabular}

Table 1

Intended and actual uptake of ISMs

25 


\begin{tabular}{|l|c|}
\hline ESMs intended & 21 \\
\hline ESMs implemented of those recommended & 15 \\
\hline Human factor error $(\mathrm{hfe})$ & 0.714 \\
\hline
\end{tabular}

Table 2

Robustness factor (r)\%

26 


\begin{tabular}{|l|c|c|}
\hline ESM & $\boldsymbol{f}$ & $\Delta \boldsymbol{C}(\boldsymbol{k t} \boldsymbol{C})$ \\
\hline Draught-proofing & 1.857 & 11.5 \\
\hline Loft insulation (DIY) & 1.571 & 12.8 \\
\hline $\begin{array}{l}\text { Loft insulation } \\
\text { (professionally installed) }\end{array}$ & 1.571 & 5.5 \\
\hline Cavity wall insulation & 2.333 & 29.0 \\
\hline Hot water tank insulation & 1.200 & - \\
\hline Double glazing & 1.039 & 14.6 \\
\hline & & 73.4 \\
\hline Total & & \\
\hline
\end{tabular}

Table 3

Energy certificate factor $(f)$ and carbon savings $(\Delta C)$ (for duration of Kyoto Protocol term (2008-2012 inclusive) 


\begin{tabular}{|l|c|c|c|c|c|c|}
\hline & $\mathbf{2 0 0 8}$ & $\mathbf{2 0 0 9}$ & $\mathbf{2 0 1 0}$ & $\mathbf{2 0 1 1}$ & $\mathbf{2 0 1 2}$ & $\mathbf{2 0 0 8 - 2 0 1 2}$ \\
\hline Draught-proofing & 0.46 & 1.38 & 2.30 & 3.22 & 4.14 & 11.5 \\
\hline Loft insulation (DIY) & 0.51 & 1.54 & 2.56 & 3.58 & 4.61 & 12.8 \\
\hline Loft insulation (prof) & 0.22 & 0.66 & 1.10 & 1.54 & 1.98 & 5.5 \\
\hline Cavity wall insulation & 1.16 & 3.48 & 5.80 & 8.12 & 10.44 & 29.0 \\
\hline Double glazing & 0.58 & 1.75 & 2.92 & 4.09 & 5.26 & 14.6 \\
\hline TOTAL & $\mathbf{2 . 9}$ & $\mathbf{8 . 8}$ & $\mathbf{1 4 . 7}$ & $\mathbf{2 0 . 6}$ & $\mathbf{2 6 . 4}$ & $\mathbf{7 3 . 4}$ \\
\hline
\end{tabular}

Table 4

Nationwide carbon savings brought about by the EPC throughout the term of the Kyoto Protocol 


\begin{tabular}{|l|c|c|c|c|}
\hline & $\begin{array}{c}\text { ESM } \\
\text { INSTALLATION } \\
\text { COST (EM)* }\end{array}$ & $\begin{array}{c}\text { FUEL COST } \\
\text { SAVINGS } \\
\text { (EM)** }\end{array}$ & $\begin{array}{c}\text { PROPORTION OF } \\
\text { INSTALLATION } \\
\text { ACHIEVED THROUGH } \\
\text { FUEL COST SAVINGS } \\
(\%)\end{array}$ & $\begin{array}{c}\text { ESM LIFETIME } \\
\text { (YEARS)*** }^{*}\end{array}$ \\
\hline $\begin{array}{l}\text { Draught- } \\
\text { proofing }\end{array}$ & 27.707 & 15.728 & 57 & 20 \\
\hline $\begin{array}{l}\text { Loft insulation } \\
\text { (DIY) }\end{array}$ & 18.351 & 17.679 & 96 & 40 \\
\hline $\begin{array}{l}\text { Loft insulation } \\
\text { (professional) }\end{array}$ & 16.188 & 7.622 & 47 & 40 \\
\hline $\begin{array}{l}\text { Cavity wall } \\
\text { insulation }\end{array}$ & 56.762 & 40.795 & 72 & 20 \\
\hline Double glazing & 81.515 & 6.538 & 8 & \\
\hline TOTAL & $\mathbf{2 0 0 . 5 2 3}$ & $\mathbf{8 8 . 3 6 2}$ & 44 & \\
\hline
\end{tabular}

* Based on DEFRA estimates for 2010 (DEFRA, 2008), using GDP deflator value of 23/4\% as forecast by HM Treasury (HM Treasury, 2008).

** Based on DEFRA estimates for 2007 (DEFRA, 2008), taking account of the 11.8\% increase in domestic energy prices from 2nd quarter 2007 to April 2008 (BERR, 2008) and using GDP deflator value of 23/4\% as forecast by HM Treasury (HM Treasury, 2008).

$* * * D E F R A, 2008$

Table 5

Comparsion of natiowide installation costs and financial savings over the course of the Kyoto Protocol term(2008-2012) 


\begin{tabular}{|c|c|}
\hline & $\begin{array}{c}\text { CARBON CONVERSION } \\
\text { FACTOR }(\boldsymbol{k}) \mathbf{( t C / v r )}\end{array}$ \\
\hline Draught-proofing & $0.43^{*}$ \\
\hline Loft insulation (DIY) & $0.086^{*}$ \\
\hline Loft insulation (professional) & $0.10^{*}$ \\
\hline Cavity wall insulation & $0.20^{*}$ \\
\hline Hot water tank insulation & $0.053^{*}$ \\
\hline Double glazing & $0.74^{* *}$ \\
\hline
\end{tabular}

* for stock-typical semi-detached house (DEFRA, 2007)

** EST, 2008

Table 6 Carbon conversion factor $(k)$ 


\begin{tabular}{|l|c|c|}
\hline ESM & $\boldsymbol{f}$ & $\begin{array}{l}\text { PAYBACK TIME } \\
\text { (YRS) }\end{array}$ \\
\hline Draught-proofing & 1.9 & 4.3 \\
\hline Loft insulation & 1.6 & 2.7 \\
\hline Cavity wall insulation & 2.3 & 2.6 \\
\hline $\begin{array}{l}\text { Windows (single to } \\
\text { double glazing) }\end{array}$ & 1.0 & $43.7^{* *}$ \\
\hline Hot water tank insulation & 1.2 & 0.5 \\
\hline
\end{tabular}

Table 7

Comparison of energy certificate factor (f) with payback time

* (DCLG 2006c).

** based on carbon savings cited by the Energy Saving Trust (EST, 2008) 


\begin{tabular}{|l|c|c|}
\hline ESM & $\boldsymbol{f}$ & $\begin{array}{l}\text { INSTALLATION } \\
\text { COST/HOUSEHOLD } \\
\text { (£) (2008 PRICES)* }\end{array}$ \\
\hline Draught-proofing & 1.9 & 98 \\
\hline Loft insulation (DIY) & 1.6 & 117 \\
\hline $\begin{array}{l}\text { Loft insulation } \\
\text { (professional) }\end{array}$ & 1.6 & 279 \\
\hline Cavity wall insulation & 2.3 & 370 \\
\hline $\begin{array}{l}\text { Windows (single to } \\
\text { double glazing) }\end{array}$ & 1.0 & $3114^{* *}$ \\
\hline $\begin{array}{l}\text { Hot water tank } \\
\text { insulation }\end{array}$ & 1.2 & 13 \\
\hline
\end{tabular}

* based on data from DEFRA, 2008

** based on data from DCLG, 2006c

Table 8

Comparison of energy certificate factor (f) with installation costs 


\section{Owner-occupier survey of energy saving measures}

1. Are you the owner-occupier of your home?

Yes/ No

(If you are a tenant rather than an owner-occupier you need not answer any more questions.)

2. How long have you lived in your home (to the nearest year)?

The following questions ask which energy saving measures you have had installed in your home.

If the energy saving measure was already in place when you moved in and you have not replaced or added to it, ignore the question.

Also ignore those questions if your home does not contain the energy saving measure.

\section{Energy saving measure}

3. Have you had loft insulation installed? (Indicate total depth if known) NO

4. Have you had cavity wall insulation installed?

5. Have you had the hot water tank insulated? Only answer the question if the hot water tank is still used (Indicate the total depth if known)

6. Have you had a few windows double glazed? (less than $50 \%$ of windows)

7. Have you had most windows double glazed? (more than 50\% of windows)

8. Have you had any draught-proofing measures installed?

Please use the space below to add any further comments you wish to make. moving in
After 23 months of moving in

Within 23 months of 